\title{
Immediate Effects of High-frequency Diathermy on Muscle Architecture and Flexibility in Subjects With Gastrocnemius Tightness
}

\author{
Ji-hyun Kim¹, BPT, PT, Joo-hee Park², PhD, PT, Hyeo-bin Yoon¹, MSc, PT, Jun-hyeok Lee ${ }^{1}$, BPT, PT, \\ Hye-seon Jeon ${ }^{2,3}, \mathrm{PhD}, \mathrm{PT}$ \\ ${ }^{1}$ Department of Physical Therapy, The Graduate School, Yonsei University, ${ }^{2}$ Department of Physical Therapy, College of Health Science, \\ Yonsei University, ${ }^{3}$ Department of Ergonomic Therapy, The Graduate School of Health and Environment, Yonsei University, Wonju, Korea
}

\section{Article Info}

Received January 15, 2020

Revised February 4, 2020

Accepted March 2, 2020

Corresponding Author

Hye-seon Jeon

E-mail: Hyeseonj@yonsei.ac.kr

https://orcid.org/0000-0003-3986-2030

\section{Key Words}

Ankle

Diathermy

Muscle tonus

Physical therapy modalities
Background: The gastrocnemius (GCM) is one of the lower extremity muscles that tend to tighten easily. GCM tightness results in limited ankle dorsi-flexion (DF), especially when the knee joint is fully extended. Joint flexibility is determined by the morphological and physiological characteristics of joints, muscles, tendons, and ligaments. Impaired joint flexibility can be attributed to increased susceptibility to muscle injury. High-frequency diathermy is clinically used to reduce pain and muscle tightness and to improve limited range of motion.

Objects: This study aimed to investigate the immediate effects of high-frequency therapy in subjects with GCM tightness.

Methods: The study was designed as a one-group before-after trial. The subjects included 28 volunteers with GCM tightness (an active ankle DF angle of less than $12^{\circ}$ ) without any known neurological and musculoskeletal pathologies in the ankle and calf areas. WINBACK Transfer Electrode Capacitive and Resistive Therapy equipment was used to apply high-frequency therapy to the subjects' GCMs for 10-15 minutes. The pennation angle and the fascicle length of the GCM were measured using ultrasonography. The flexibility of the ankle joint, peak torque to the passive ankle DF (Biodex), and soft tissue stiffness (MyotonPRO) were also measured.

Results: The pennation angle was significantly decreased following the treatment; however, no significant difference in the fascicle length was found $(p<0.05)$. The flexibility was significantly increased and both the passive peak torque to passive ankle DF and the soft tissue stiffness significantly decreased ( $p<0.05)$.

Conclusion: High-frequency therapy is immediately effective for improving the muscle's architectural properties and functional factors in subjects with GCM tightness. Further longitudinal clinical studies are required to investigate the long-term effects of high-frequency therapy on subjects with GCM tightness from various causes.

\section{INTRODUCTION}

Muscle tightness is a common symptom that causes musculoskeletal injuries and is defined as an abnormally shortened muscle length that limits the range of motion (ROM) [1,2]. Muscle tightness results from overuse of specific muscles, poor posture, decreased flexibility, and spasticity [2-6]. Muscle architecture, such as pennation angle (PA) and fascicle length (FL), changes with the muscle contraction state [7]. The PA is the angle of muscle fibers aligned between two aponeuroses in a pennate muscle [8]. During the active shortening contraction of a pennate muscle, the PA between two aponeuroses increases as the FL shortens [8,9].

Gastrocnemius (GCM) is one of the lower extremity muscles that tends to tighten easily [10]. GCM tightness results in limited ankle dorsi-flexion (DF), especially when the knee joint is fully extended [11]. It is also related to various musculoskeletal disorders, such as Achilles tendinitis, muscle strains, iliotibial band friction syndrome, patellofemoral syndrome, and plantar fasciitis [4,12-15]. In various central nerve system lesions, spasticity in the GCM is a main impairment that produces tightness in the long term, and GCM tightness affects functional abilities in standing or walking [16].

Joint flexibility is influenced by joint architecture and mus- 
cles, tendons, and ligaments [17]. It can be affected by muscle stiffness or susceptibility to muscle injury [18-21]. These factors are important in rehabilitation because they can result in injury by causing early fatigue of muscles or by altering the biomechanics of normal motion [4]. Stretching exercises, relaxation techniques, and heat therapy have been considered for releasing GCM tightness [1,22-24]. High-frequency diathermy (HFD) is an electrical heat treatment device that transfers high-frequency currents to the deep tissue level, and clinicians use it to produce heat in deep human body tissue [25,26]. HFD has been applied clinically to increase blood flow and the extensibility of collagen tissues and to decrease muscle tone and pain [27-30]. A few studies have compared the muscle architecture between the paretic and non-paretic limb muscles of neurological patients, and other experiments have examined the changes in muscle architecture accordance with the joint angle [31-33]. However, no previous studies have investigated the effects of HFD on muscle architectural changes and joint flexibility in subjects with GCM tightness. The present experimental study therefore aimed to investigate the immediate effects of the HFD on GCM architecture, ankle joint flexibility, peak torque to the passive ankle DF, and soft tissue stiffness in subjects with GCM tightness.

\section{MATERIALS AND METHODS}

\section{Subjects}

Twenty-eight healthy subjects with GCM tightness were recruited from university populations. The mean age of the participants was 22.9 years (21-28 years). Based on previous studies, we included subjects with active ankle DF angles of less than $12^{\circ}$ at full knee extension [34]. Subjects with (1) GCM tightness due to a neurological problem; (2) hypersensitivity;
(3) a history of arthritis, injury, or surgery on the calf or ankle; or (4) a metal insert in the area requiring therapy were the excluded from this study. All subjects read an explanation of the experimental procedures and signed an informed consent form approved by the Yonsei University Wonju Institutional Review Board (approval No. 1041849-201810-BM-096-02).

\section{High-frequency Diathermy Therapy}

In this experiment, WINBACK Transfer Electrode Capacitive and Resistive (TECAR) Therapy (radio frequence therapeutique; WINBACK, Villeneuve Loubet, France) was used to apply the HFD therapy. WINBACK TECAR therapy is a systematic treatment for providing capacitive energy transfer (CET) and resistive energy transfer (RET) [26]. In CET mode, heat transfer is concentrated on the skin and superficial muscles, which are tissue with high electrolytes, while the RET mode focuses heat transfer on bones, tendons, joints, and deep muscles [26]. In this study, both CET and RET modes were applied to the patients' GCM for 10-15 minutes at $0.3 \mathrm{MHz}$. According to the manufacturer's guidelines for safety, the CET mode was first implemented for 5 minutes using two mobile electrodes. HFD was then continued in RET mode using two mobile electrodes for the rest of the treatment. Subjects were asked to lie down comfortably, and treatment began. The intensity of the current was set at the level of comfort between 0\%-100\%, averaging about $40 \%$. HFD was applied by a physical therapist for all subjects.

\section{Outcome Measures}

\section{1) Muscle architecture (pennation angle and fascicle length)}

PA and FL of the medial GCM were measured using ultrasonography (US) (Mysono U6; Medison, Seoul, Korea) in the
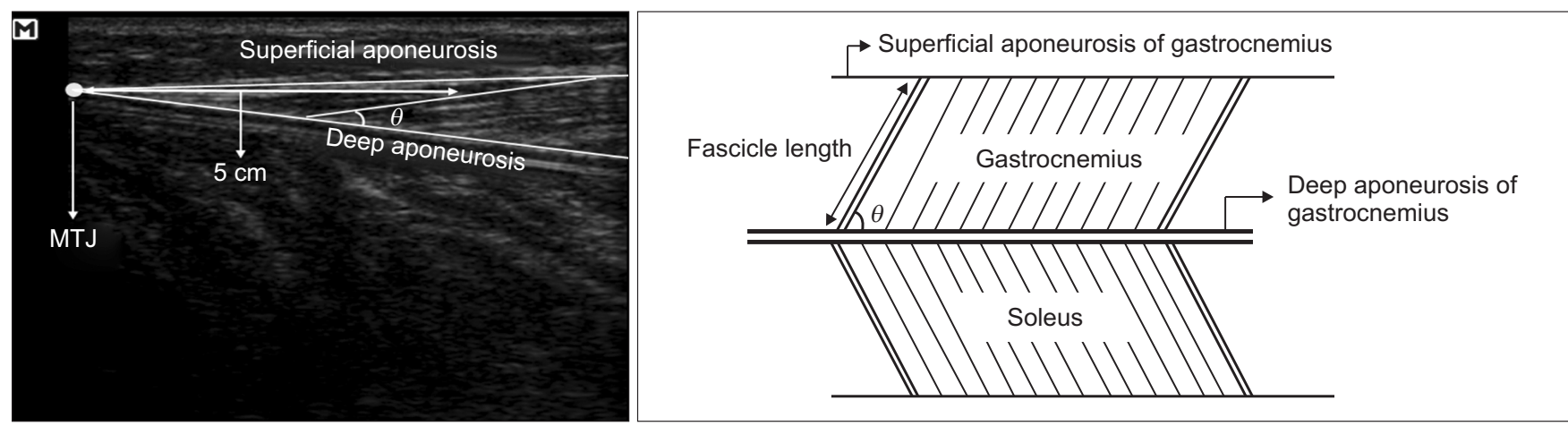

Figure 1. Architecture of gastrocnemius (A: ultra-sonography view, B: schematic of triceps surae). MTJ: musculo-tendon junction, $\theta$ : pennation angle. 
prone position while the ankle joint maintained a neutral position. A 5-12 MHz linear transducer was placed perpendicularly at the middle part of the GCM to identify the muscle. Fascicles were arranged diagonally between the superficial and deep aponeuroses of the GCM (Figure 1). FL was measured at $5 \mathrm{~cm}$ proximal to the musculotendon junction [35]. The PA was the angle between the fascicle line and deep aponeurosis [36].

\section{2) Range of motion}

The maximum joint ROM value represents the musculoskeletal flexibility of the joint [37]. Under the assumption that the ankle joint ROM was limited by GCM tightness, the maximum ankle DF ROM was measured using a universal goniometer in two conditions: (1) DF ROM in squat (weight-bearing position) and (2) passive ROM in prone (non-weight bearing position). For the ROM test in squat, the subjects were asked to squat down from standing straight with their bare feet the same distance apart as the width of the pelvis. We measured the ankle DF ROM just before the heel lost the contact with the floor. Passive ankle ROM at maximum DF was measured in the prone position with full knee extension on a plinth.

\section{3) Peak torque to the passive ankle dorsi-flexion}

A Biodex System Isokinetic Dynamometer (Biodex Medical, Shirley, NY, USA) was used to assess the peak torque to the passive ankle DF. First, the subjects sat on the Biodex device with a restraining strap over the knee and ankle in accordance with the Biodex user's guide. Passive unilateral ankle movements were repeated 30 times between $25^{\circ}$ plantar flexion and $15^{\circ} \mathrm{DF}$ at $60^{\circ} / \mathrm{sec}$. The average peak torque value to the passive ankle DF was used for data analysis.

\section{4) Soft tissue stiffness}

A MyotonPRO (Myoton AS, Estonia) is a portable hand-held myotonometer that can assess muscle tone and soft tissue stiffness. According to prior research, the MyotonPRO is a reliable quantitative measurement for assessing the mechanical properties of muscles [38]. We collected and analyzed all data obtainable from the MyotonPRO: muscle tone, tissue stiffness, and relaxation time. The muscle tone can be expressed as a natural oscillation frequency $(\mathrm{Hz})$, which is measured in a resting state without any voluntary contraction. The stiffness $(\mathrm{N} / \mathrm{m})$ is characterized by resistance to an external force that can deform the original shape and refers to the relationship between passive resistive torque and joint displacement [39,40].

The subjects lay prone on an assessment table with their feet hanging off the table at an ankle neutral position. Myotonometer data was obtained from the testing leg at three marked measurement points of the GCM-the upper, middle, and lower parts of the testing leg. The tip of the device was placed vertically on each measurement point and then produced five damped oscillations. The measurement was taken using the five-scan mode with an indentation force of $0.4 \mathrm{~N}$ at 0.8 seconds intervals. We used the average values of 15 repeated measurements (three points $\times$ five scans).

\section{Statistical Analysis}

The data was analyzed using Windows SPSS version 24.0 (IBM Co., Armonk, NY, USA). A Kolmogorov-Smirnov test was performed to confirm the normal distribution of the experimental participants. A paired t-test was used to compare the dependent variables before and after the treatment. The significance level was set at 0.05 .

\section{RESULTS}

The muscle architectural variables using US are shown in Table 1. First, the PA in the neutral ankle position was significantly changed after the HFD, but the FL was not significantly changed ( $p>0.05)$.

All subjects demonstrated a significant improvement in passive and active ROM. The peak torque to the ankle DF after the HFD was less than the peak torque before the HFD $(p<0.05)$ (Table 2).

As shown below in Table 3, the differences between pre- and post-test for all variables collected from MyotonPRO were statistically significant $(\mathrm{p}<0.05)$.

\section{DISCUSSION}

The present study investigated the clinical effectiveness of HFD using a WINBACK TECAR device in subjects with GCM

Table 1. Ultrasonography data

\begin{tabular}{lrrc}
\hline \multicolumn{1}{c}{ Variables } & \multicolumn{1}{c}{ Pre data } & Post data & p-value \\
\hline Pennation angle $\left({ }^{\circ}\right)$ & $19.83 \pm 4.82$ & $16.46 \pm 5.85$ & 0.000 \\
Fascicle length $(\mathrm{mm})$ & $1.95 \pm 1.67$ & $2.45 \pm 2.52$ & 0.381 \\
\hline
\end{tabular}

Values are presented as mean \pm standard deviation. 
Table 2. Ankle joint range of motion and joint passive stiffness

\begin{tabular}{lrrr}
\hline Variables & Pre data & Post data & p-value \\
\hline Range of motion $\left({ }^{\circ}\right)$ & & & \\
DF ROM in squat & $25.61 \pm 9.20$ & $31.93 \pm 8.27$ & 0.000 \\
Passive ROM & $8.39 \pm 6.34$ & $13.21 \pm 5.85$ & 0.000 \\
Joint passive stiffness & $14.21 \pm 2.95$ & $12.8 \pm 2.78$ & 0.000 \\
\hline
\end{tabular}

Values are presented as mean \pm standard deviation. DF, dorsi-flexion; $\mathrm{ROM}$, range of motion.

tightness. To our knowledge, this is the first study that has applied HFD using a WINBACK TECAR for treating GCM tightness. Taken together, the findings of this study indicate that HFD could improve muscle architecture, joint flexibility, and soft tissue stiffness. More specifically, PA and ROM increased, and peak torque to the passive DF, muscle tone, and stiffness decreased, after applying a 15-minute session of HFD.

According to previous studies, HFD increases microcirculation and vasodilatation, thereby increasing body temperature and reducing pain [26,41]. It passes alternating current through human tissue and converts it into thermal energy, which creates deep heat to relax tight muscles, ligaments, and tendons, thus activating autonomic nerves and sympathetic nerves [42]. According to Gutmann [43], the local temperature of the body increased by $3^{\circ}-5^{\circ}$ after HFD was applied for 15 minutes and the increase in temperature had not reversed 3-4 hours after treatment. Decreased PA after HFD indirectly indicates a more relaxed GCM, which would reduce muscle tone and stiffness, resulting in an increase in the ankle DF ROM. FL also increased after the treatment. But the FL change was not statistically significant, which could be partially explained by relatively high between-subject variability in gender and muscle volume. It is very important to understand the structure-function relationship because muscle architecture is a primary determinant of muscle function. Previous studies that have investigated muscle architecture parameters, such as PA, FL, and cross-sectional area [44-48], have revealed that muscle architecture also has a significant impact on the way muscle forces are transmitted to tendons and bones $[47,49]$. These muscle architectural parameters also affect the functional proficiency of the muscle in generating maximal muscle tension and muscle shortening at maximal velocity $[50,51]$. For instance, the larger the PA, the greater the reduction in force development [52].

Muscle stiffness causes a decrease in joint flexibility [18-21], and early muscle fatigue and can change the biomechanics of normal motion [4]. The likelihood of muscle injuries increases
Table 3. Hand-held myotonometer data

\begin{tabular}{lllc}
\hline \multicolumn{1}{c}{ Variables } & \multicolumn{1}{c}{ Pre data } & \multicolumn{1}{c}{ Post data } & p-value \\
\hline Muscle tone $(\mathrm{Hz})$ & $19.67 \pm 1.91$ & $18.15 \pm 1.6$ & 0.000 \\
Stiffness $(\mathrm{N} / \mathrm{m})$ & $380.7 \pm 52.27$ & $335.3 \pm 40.41$ & 0.000 \\
Relaxation time $(\mathrm{ms})$ & $14.64 \pm 1.58$ & $16.11 \pm 1.45$ & 0.000 \\
\hline
\end{tabular}

Values are presented as mean \pm standard deviation.

with muscle stiffness [4], whereas increasing joint flexibility can improve physical performance, reduce the risk of musculoskeletal injury [53,54], allow muscles to function more efficiently on the length-tension curve, and reduce the chance of a tear-type injury [55,56]. Increased flexibility achieved by muscle stretching exercises also reduces musculoskeletal injuries [41,57]. Lehmann [41] stated that the maximum stretch is achieved without tissue damage when the local temperature of the connective tissue is $40^{\circ} \mathrm{C}-50^{\circ} \mathrm{C}$-the tissue's optimal functional recovery temperature. Therefore, HFD applied simultaneously with stretching exercises would augment the effectiveness of treatment. WINBACK TECAR therapy has an automatic mode, making it possible to perform stretching exercises at the same time as having an electrode attached to the body to deliver high-frequency current to the tight muscle area. We suggest that a further study be conducted on the effects of HFD combined with stretching exercises. The limitation of this study is to investigate only the short-term effects. Thus, further randomized controlled studies with large sample sizes are also recommended in different muscles to explore the long-term effects of the HFD in various pathologies and injuries.

\section{CONCLUSIONS}

This study demonstrated that HFD has a positive effect. HFD is clinically effective in terms of improving the PA, joint flexibility, muscle tone, stiffness, and joint torque of subjects with GCM tightness in a short period of time. However, the present study used a one-group pretest-posttest design. Longitudinal clinical studies are required to investigate the long-term effects of HFD on subjects with GCM tightness from various causes.

\section{CONFLICTS OF INTEREST}

No potential conflict of interest relevant to this article was reported. 


\section{AUTHOR CONTRIBUTIONS}

Conceptualization: JK, HJ, JP, HY, JL. Data curation: JK, HY. Formal analysis: JK, JL. Investigation: JK, HY, JL. Methodology: HJ, JP. Supervision: HJ, JP. Visualization: JL. Writing - original draft: JK. Writing - review \& editing: JK, HJ.

\section{ORCID}

Ji-hyun Kim, https://orcid.org/0000-0003-2701-4317

Joo-hee Park, https://orcid.org/0000-0001-9545-1362

Hyeo-bin Yoon, https://orcid.org/0000-0001-8421-0731

Jun-hyeok Lee, https://orcid.org/0000-0002-9567-0845

\section{REFERENCES}

1. Kim WH, Park YT, Hwang SY, Kwon HC. Comparison of effects for application of proprioceptive neuromuscular facilitation technique and static stretching on the calf muscle. Phys Ther Korea 1995;2(2):56-65.

2. Wang SS, Whitney SL, Burdett RG, Janosky JE. Lower extremity muscular flexibility in long distance runners. J Orthop Sports Phys Ther 1993;17(2):102-7.

3. Baddar A, Granata K, Damiano DL, Carmines DV, Blanco JS, Abel MF. Ankle and knee coupling in patients with spastic diplegia: effects of gastrocnemius-soleus lengthening. J Bone Joint Surg Am 2002;84(5):736-44.

4. Ekstrand J, Gillquist J. The frequency of muscle tightness and injuries in soccer players. Am J Sports Med 1982;10(2):75-8.

5. Hertling D, Kessler RM. Management of common musculoskeletal disorders: physical therapy principles and methods. Philadelphia: Lippincott Williams \& Wilkins; 2006.

6. Moseley AM, Crosbie J, Adams R. High- and low-ankle flexibility and motor task performance. Gait Posture 2003;18(2):7380.

7. Gans C, Bock WJ. The functional significance of muscle architecture--a theoretical analysis. Ergeb Anat Entwicklungsgesch 1965;38:115-42.

8. Kawakami Y, Ichinose Y, Fukunaga T. Architectural and functional features of human triceps surae muscles during contraction. J Appl Physiol (1985) 1998;85(2):398-404.

9. Fukunaga T, Ichinose Y, Ito M, Kawakami Y, Fukashiro S. Determination of fascicle length and pennation in a contracting human muscle in vivo. J Appl Physiol (1985) 1997;82(1):354-8.
10. DiGiovanni CW, Kuo R, Tejwani N, Price R, Hansen ST Jr, Cziernecki J, et al. Isolated gastrocnemius tightness. J Bone Joint Surg Am 2002;84(6):962-70.

11. Baumbach SF, Braunstein M, Seeliger F, Borgmann L, Böcker W, Polzer H. Ankle dorsiflexion: what is normal? Development of a decision pathway for diagnosing impaired ankle dorsiflexion and M. gastrocnemius tightness. Arch Orthop Trauma Surg 2016;136(9):1203-11.

12. Kaufman KR, Brodine SK, Shaffer RA, Johnson CW, Cullison TR. The effect of foot structure and range of motion on musculoskeletal overuse injuries. Am J Sports Med 1999;27(5):58593.

13. Lun V, Meeuwisse WH, Stergiou P, Stefanyshyn D. Relation between running injury and static lower limb alignment in recreational runners. Br J Sports Med 2004;38(5):576-80.

14. Neely FG. Biomechanical risk factors for exercise-related lower limb injuries. Sports Med 1998;26(6):395-413.

15. Riddle DL, Pulisic M, Pidcoe P, Johnson RE. Risk factors for Plantar fasciitis: a matched case-control study. J Bone Joint Surg Am 2003;85(5):872-7.

16. Kocabas H, Salli A, Demir AH, Ozerbil OM. Comparison of phenol and alcohol neurolysis of tibial nerve motor branches to the gastrocnemius muscle for treatment of spastic foot after stroke: a randomized controlled pilot study. Eur J Phys Rehabil Med 2010;46(1):5-10.

17. Krivickas LS, Feinberg JH. Lower extremity injuries in college athletes: relation between ligamentous laxity and lower extremity muscle tightness. Arch Phys Med Rehabil 1996;77(11):1139-43.

18. Magnusson SP, Simonsen EB, Aagaard P, Boesen J, Johannsen F, Kjaer M. Determinants of musculoskeletal flexibility: viscoelastic properties, cross-sectional area, EMG and stretch tolerance. Scand J Med Sci Sports 1997;7(4):195-202.

19. Miyamoto N, Hirata K, Kanehisa H. Effects of hamstring stretching on passive muscle stiffness vary between hip flexion and knee extension maneuvers. Scand J Med Sci Sports 2017;27(1):99-106.

20. Watsford ML, Murphy AJ, McLachlan KA, Bryant AL, Cameron ML, Crossley KM, et al. A prospective study of the relationship between lower body stiffness and hamstring injury in professional Australian rules footballers. Am J Sports Med 2010;38(10):2058-64.

21. Witvrouw E, Danneels L, Asselman P, D'Have T, Cambier D. Muscle flexibility as a risk factor for developing muscle inju- 
ries in male professional soccer players. A prospective study. Am J Sports Med 2003;31(1):41-6.

22. Nakamura M, Ikezoe T, Takeno Y, Ichihashi N. Effects of a 4-week static stretch training program on passive stiffness of human gastrocnemius muscle-tendon unit in vivo. Eur J Appl Physiol 2012;112(7):2749-55.

23. Park B. The acute effects of static stretching and dynamic stretching with a moist heat pack in young healthy people with limited flexibility of the triceps surae. Omaha, University of Nebraska at Omaha, Master's thesis. 2018.

24. Skaria LA. Effectiveness of post-isometric relaxation over passive stretching for gastrocemius tightness in unimpaired individuals-a comparative study. Bangalore, Rajiv Gandhi University of Health Sciences, Master's thesis. 2005.

25. Tranquilli C, Ganzit GP, Ciufetti A, Bergamo P, F. Combi Italian Football Federation. Multicentre study on tecar ${ }^{\circledR}$ therapy in sports pathologies. Tecar UK [internet]. 2009 [cited 2019 Apr]. Available from: https://pdfs.semanticscholar.org/225c/ 9dacfff20e9b3218aa1074343a2dba02b831.pdf?_ga= 2.208975889.2034982032.1586147148-1347939954. 1538136160.

26. Ganzit GP, Stefanini L, Stesina G. Tecar ${ }^{\circledR}$ therapy in the treatment of acute and chronic pathologies in sports. Tecar UK [internet]. 2000 [cited 2019 Apr]. Available from: https:// docplayer.net/59319138-Tecar-therapy-in-the-treatment-ofacute-and-chronic-pathologies-in-sports.html.

27. Akyürekli D, Gerig LH, Raaphorst GP. Changes in muscle blood flow distribution during hyperthermia. Int J Hyperthermia 1997;13(5):481-96.

28. Brown M, Baker RD. Effect of pulsed short wave diathermy on skeletal muscle injury in rabbits. Phys Ther 1987;67(2):20814.

29. Strickler T, Malone T, Garrett WE. The effects of passive warming on muscle injury. Am J Sports Med 1990;18(2):1415 .

30. Wilson DH. Treatment of soft-tissue injuries by pulsed electrical energy. Br Med J 1972;2(5808):269-70.

31. Gao F, Grant TH, Roth EJ, Zhang LQ. Changes in passive mechanical properties of the gastrocnemius muscle at the muscle fascicle and joint levels in stroke survivors. Arch Phys Med Rehabil 2009;90(5):819-26.

32. Kwah LK, Herbert RD, Harvey LA, Diong J, Clarke JL, Martin $\mathrm{JH}$, et al. Passive mechanical properties of gastrocnemius muscles of people with ankle contracture after stroke. Arch
Phys Med Rehabil 2012;93(7):1185-90.

33. Li L, Tong KY, Hu X. The effect of poststroke impairments on brachialis muscle architecture as measured by ultrasound. Arch Phys Med Rehabil 2007;88(2):243-50.

34. Johanson M, Baer J, Hovermale H, Phouthavong P. Subtalar joint position during gastrocnemius stretching and ankle dorsiflexion range of motion. J Athl Train 2008;43(2):172-8.

35. Kawakami Y, Kumagai K, Huijing PAJBM, Hijikata T, Fukunaga T. The length-force characteristics of human gastrocnemius and soleus in vivo. In: Herzog W, editor. Skeletal muscle mechanics: from mechanisms to function. New York: Wiley; 2000;327-41.

36. Gao F, Zhang LQ. Altered contractile properties of the gastrocnemius muscle poststroke. J Appl Physiol (1985) 2008;105(6):1802-8

37. Liemohn W. Flexibility/range of motion. In: Durstine JL, King AC, Painter PL, Roitman JL, Zwiren LD, Kenney WL, editors. ACSM's resource manual for guidelines for exercise testing and prescription. 2nd ed. Philadelphia: Lea and Febiger; 1993;327-36.

38. Pruyn EC, Watsford ML, Murphy AJ. Validity and reliability of three methods of stiffness assessment. J Sport Health Sci 2016;5(4):476-83.

39. Bressel E, McNair PJ. Biomechanical behavior of the plantar flexor muscle-tendon unit after an achilles tendon rupture. Am J Sports Med 2001;29(3):321-6.

40. Nordez A, Cornu C, McNair P. Acute effects of static stretching on passive stiffness of the hamstring muscles calculated using different mathematical models. Clin Biomech (Bristol, Avon) 2006;21(7):755-60.

41. Lehmann JF, DeLateur BJ. Diathermy and superficial heat, laser, cold therapy. In: Krusen FH, Kottke JF, Lehmann JF, editors. Krusen's handbook of physical medicine and rehabilitation. 4th ed. Philadelphia: Saunders; 1990;283-435.

42. Chung E. The effects of high frequency therapy on abdomen circumfence changes of women obesity. Seoul, Chung-ang university, Master's thesis. 2006.

43. Gutmann AZ. Recientes avances en fisioterapia. Fisioterapia actual. 1993;3:321-332.

44. Amis AA, Dowson D, Wright V. Muscle strengths and musculoskeletal geometry of the upper limb. Eng Med 1979;8(1):418.

45. An KN, Hui FC, Morrey BF, Linscheid RL, Chao EY. Muscles across the elbow joint: a biomechanical analysis. J Biomech 
1981;14(10):659-69.

46. Brand RA, Pedersen DR, Friederich JA. The sensitivity of muscle force predictions to changes in physiologic cross-sectional area. J Biomech 1986;19(8):589-96.

47. Jacobson MD, Raab R, Fazeli BM, Abrams RA, Botte MJ, Lieber RL. Architectural design of the human intrinsic hand muscles. J Hand Surg Am 1992;17(5):804-9.

48. Lieber RL. Skeletal muscle structure and function: implications for rehabilitation and sports medicine. Baltimore: Williams \& Wilkins; 1992.

49. Lieber RL, Brown CC. Quantitative method for comparison of skeletal muscle architectural properties. J Biomech 1992; 25(5):557-60.

50. Burkholder TJ, Fingado B, Baron S, Lieber RL. Relationship between muscle fiber types and sizes and muscle architectural properties in the mouse hindlimb. J Morphol 1994; $221(2): 177-90$.
51. Sacks RD, Roy RR. Architecture of the hind limb muscles of cats: functional significance. J Morphol 1982;173(2):185-95.

52. Kawakami Y, Abe T, Fukunaga T. Muscle-fiber pennation angles are greater in hypertrophied than in normal muscles. J Appl Physiol (1985) 1993;74(6):2740-4.

53. Shellock FG, Prentice WE. Warming-up and stretching for improved physical performance and prevention of sportsrelated injuries. Sports Med 1985;2(4):267-78.

54. Smith CA. The warm-up procedure: to stretch or not to stretch. A brief review. J Orthop Sports Phys Ther 1994;19(1):12-7.

55. Rooks DS, Micheli LJ. Musculoskeletal assessment and training: the young athlete. Clin Sports Med 1988;7(3):641-77.

56. Safran MR, Seaber AV, Garrett WE Jr. Warm-up and muscular injury prevention. An update. Sports Med 1989;8(4):239-49.

57. Hartig DE, Henderson JM. Increasing hamstring flexibility decreases lower extremity overuse injuries in military basic trainees. Am J Sports Med 1999;27(2):173-6. 